\title{
Biomarkers as potential treatment targets in inflammatory bowel disease: A systematic review
}

\author{
Travis B Murdoch MD MSc ${ }^{1 *}$, Sarah O'Donnell MD ${ }^{2 *}$, Mark S Silverberg MD PhD², Remo Panaccione MD
}

TB Murdoch, S O’Donnell, MS Silverberg, R Panaccione. Biomarkers as potential treatment targets in inflammatory bowel disease: A systematic review. Can J Gastroenterol Hepatol 2015;29(4):203-208

There is increasing interest in the concept of 'treat-to-target' in inflammatory bowel disease as a mechanism to standardize management and prevent complications. While clinical, radiographic and endoscopic treatment end points will figure prominently in this promising management paradigm, the role that noninvasive biomarkers will play is currently undefined. The goal of the present systematic review was to investigate the potential value of biomarkers as treatment targets in inflammatory bowel disease, with particular focus on those best studied: serum C-reactive protein (CRP) and fecal calprotectin. In Crohn disease, elevated CRP levels at baseline predict response to anti-tumour necrosis factor agents, and normalization is usually associated with clinical and endoscopic remission. CRP and hemoglobin levels can be used to help predict clinical relapse in the context of withdrawal of therapy. Ultimately, the authors conclude that currently available biomarkers should not be used as treatment targets in inflammatory bowel disease because they have inadequate operational characteristics to make them safe surrogates for clinical, endoscopic and radiographic evaluation. However, CRP and fecal calprotectin are important adjunctive measures that help alert the clinician to pursue further investigation.

Key Words: Anti-tumour necrosis factor therapy; Biomarker; C-reactive protein; Crohn disease; Fecal calprotectin; Ulcerative colitis

\author{
Les biomarqueurs comme cibles thérapeutiques \\ potentielles en cas de maladies inflammatoire de \\ l'intestin : une analyse systématique
}

\begin{abstract}
On constate un intérêt croissant pour le concept de " traitement ciblé * (treat-to-target) en cas de maladies inflammatoires de l'intestin, utilisé comme mécanisme pour standardiser la prise en charge et prévenir les complications. Les indicateurs de traitement clinique, radiographique et endoscopique occupent une place de choix dans ce paradigme de prise en charge prometteur, mais le rôle des biomarqueurs non invasifs n'est toujours pas défini. La présente analyse systématique visait à examiner la valeur potentielle des biomarqueurs comme cibles thérapeutiques en cas de maladies inflammatoires de l'intestin, notamment celles qui sont les mieux étudiées, soit la protéine $\mathrm{C}$ réactive (PCR) sérique et la calpropectine fécale. Dans le cas de la maladie de Crohn, des taux de PCR élevés en début d'étude sont indicateurs d'une réponse aux agents des inhibiteurs du facteur de nécrose tumorale, et leur normalisation s'associe généralement à une rémission clinique et endoscopique. La PCR et les taux d'hémoglobine peuvent contribuer à prédire les récidives cliniques lors du sevrage thérapeutique. En définitive, les auteurs concluent que les biomarqueurs actuellement offerts ne devraient pas être utilisés comme cibles thérapeutiques en cas de maladies inflammatoires de l'intestin parce qu'en raison de leurs caractéristiques opérationnelles, ils ne peuvent pas se substituer en toute sécurité à l'évaluation clinique, endoscopique et radiographique. Cependant, la PCR et la calpropectine fécale sont des mesures complémentaires importantes qui indiquent au clinicien d'approfondir les examens.
\end{abstract}

The inflammatory bowel diseases (IBD), encompassing Crohn dis1 ease (CD) and ulcerative colitis (UC), remain a challenging group of conditions to treat. Despite many therapeutic modalities, there is uncertainty in terms of proper treatment end points. Endoscopic evaluation, combined with diagnostic imaging modalities, remain important methods to quantify the severity of disease and, by corollary, to determine response and remission following initiation of medical treatment. There is increasing recognition and uptake of the 'treat-to-target' paradigm - a concept borrowed from the rheumatology literature (1) - in guiding the management of IBD.

Biomarkers are defined as measureable substances derived from a biofluid or tissue specimens. This broad definition can include common laboratory work, such as hemoglobin concentration, or even molecular systems biology techniques, such as gene-expression profiling (eg, on peripheral blood cells). They are becoming especially important as less-invasive, cost-effective and resource-saving modalities to determine therapeutic response in IBD are developed. The aim of the present systematic review was to investigate the potential value of biomarkers as treatment targets in IBD, with discussion of their role in monitoring response to therapy and predicting relapse. We focus on assays that are widely available and used in current practice, especially serum C-reactive protein (CRP) and fecal calprotectin (fcalpro), with briefer mention of other assays (see Table 1 for summary of evidence).

\section{METHODS}

The present systematic review was performed under the aegis of the Selecting Therapeutic Targets in Inflammatory Bowel Disease (STRIDE) program, sponsored by the International Organization for the Study of Inflammatory Bowel Diseases. The systematic search strategy aimed to answer the question regarding the role of biomarkers as potential treatment targets in IBD. The initial search revealed 228 references that were manually screened by two of the study authors (SOD and TM). The search strategy used is presented in Appendix 1, and 50 relevant publications were found. Reference lists of studies and relevant review articles were reviewed. The search was limited to studies published before January 1, 2014.

\section{Summary}

\section{SERUM BIOMARKERS}

In CD and UC, CRP should not be used alone as a treatment target because it has inadequate operational characteristics to act as a surrogate for endoscopic, radiographic or clinical end points. CRP is a noninvasive adjunctive measure that can be used in both CD and UC to guide the need for further endoscopic or radiographic evaluation. Failure of CRP normalization following therapy initiation should prompt further endoscopic and/or radiographic evaluation, irrespective of symptoms. Other biomarkers, such as erythrocyte sedimentation rate (ESR), have inadequate evidence to support their use.

*Authors who contributed equally to this work

${ }^{1}$ Inflammatory Bowel Disease Clinic, Division of Gastroenterology, University of Calgary, Calgary, Alberta; ${ }^{2}$ Zane Cohen Centre for Digestive Diseases, Mount Sinai Hospital, Toronto, Ontario

Correspondence: Dr Remo Panaccione, Inflammatory Bowel Disease Clinic, Division of Gastroenterology, University of Calgary, 6th Floor, Teaching, Research and Wellness Building, 3280 Hospital Drive Northwest, Calgary, Alberta T2N 4Z6. Telephone 403-944-1110, e-mail rpanacci@ucalgary.ca Received for publication December 19, 2014. Accepted January 30, 2015 
TABLE 1

Summary and evidence level of inflammatory bowel disease biomarkers

Blood biomarkers

Evidence level

Crohn disease

There is a correlation between endoscopic but not histological disease activity and CRP levels in Crohn disease (6)

$3 b$

$1 b$

$1 b$

$2 b$

$3 b$

$2 b$

Elevation in CRP $>5 \mathrm{mg} / \mathrm{L}$, hemoglobin level $\leq 145 \mathrm{~g} / \mathrm{L}$, and leukocyte count $>6 \times 10^{9} / \mathrm{L}$ predict relapse in patients on combination therapy in whom anti-TNF therapy is discontinued (25)

Elevation of CRP $>20 \mathrm{mg} / \mathrm{L}$ and hemoglobin level $<120 \mathrm{~g} / \mathrm{L}$ are predictors of relapse in whom azathioprine is withdrawn $(22,24)$

Ulcerative colitis

CRP is associated with active disease on endoscopy $(7,37)$

Elevated CRP, low albumin and low hemoglobin levels are predictive of colectomy in acute severe ulcerative colitis (31-36)

$2 \mathrm{~b}$

$2 b$

Few randomized controlled trials in ulcerative colitis have biomarkers as end points. Small studies have found that clinical response to therapy

correlates with a reduction in CRP level $(26,28,29)$

Fecal biomarkers

\section{Crohn disease}

Fcalpro is positively associated with endoscopic activity and Crohn disease activity index $(6,43)$

Change in level correlates with change in endoscopic activity $(47,48)$

Elevated fcalpro is associated with a higher one-year risk of relapse in Crohn disease $(51,64)$

Ulcerative colitis

Fcalpro correlates with endoscopic disease and healing $(46,52,53)$

In trials of vedolizumab, changes in fcalpro correlate with Mayo score (22)

Normalization of fcalpro predicts clinical response to therapy and sustained remission $(51,53,54)$

In patients on maintenance infliximab, fcalpro was better than CRP at predicting relapse.

CRP C-reactive protein; Fcalpro Fecal calprotectin; TNF Tumour necrosis factor

In $\mathrm{CD}$, elevated CRP levels at baseline predict response to antitumour necrosis factor (TNF) agents, and normalization of CRP is modestly associated with clinical and endoscopic remission. CRP and hemoglobin levels can be used to help predict clinical relapse in the context of withdrawal of therapy.

In UC, the utility of CRP as an adjunctive measure is greatest in severe disease, in which persistent elevation, in addition to low albumin levels, is associated with the need for colectomy. CRP normalization is modestly correlated with clinical remission and mucosal healing.

\section{Discussion}

CRP: CRP is a 224-residue protein synthesized by the liver and named for its ability to precipitate the C-polysaccharide of Streptococcus pneumoniae (2). It was the first acute-phase reactant to be described, and is known to be elevated in most acute-phase responses, including infections, inflammatory diseases, trauma and malignancy. It is believed to be more accurate than other acute-phase reactants, such as ESR, which is susceptible to diurnal and nutritional variation (2), and lacks data supporting its use. Given these characteristics, as well as its popularization as a cardiovascular screening tool, CRP has become the acute-phase biomarker of choice for a broad range of diseases. CRP is of limited utility in some individuals because common polymorphisms are known to affect CRP levels and prevent an inflammation-induced rise in CRP $(3,4)$. As such, documenting an elevated CRP level in the context of a flare is an important baseline to instruct the future utility of this assay.

CRP in CD: In CD, there is evidence that extraenteric inflammation according to computed tomography enterography correlates with CRP (5), and CRP is more often elevated in individuals with colonic involvement. There is modest correlation between endoscopic disease activity and CRP levels in CD $(6,7)$.

The majority of randomized clinical trials (RCTs) in the past decade have included serial CRP measurements. Recent trials of biologic and nonbiologic therapy have increasingly used baseline elevated CRP level as an inclusion criterion to insure patients entered into these trials have an objective marker of inflammation. This practice largely stems from results of the phase II induction studies of certolizumab published in the mid-2000s, in which patients with elevated CRP levels were shown to have more robust response rates $(8,9)$. A phase II study by Schreiber et al (9) demonstrated a high placebo response rate in subgroups of patients with low CRP and, in post hoc analysis, a significant effect of therapy only in the subgroup of patients with baseline $\mathrm{CRP}>10 \mathrm{mg} / \mathrm{L}$. A further certolizumab induction trial by Sandborn et al (8) (Pegylated Antibody Fragment Evaluation in Crohn's Disease: Safety and Efficacy 1 [PRECISE 1]) stratified randomization of patients according to baseline CRP ( $\geq$ or $<10 \mathrm{mg} / \mathrm{L}$ ), and found a significant response among patients with an elevated CRP level. Both studies demonstrated a durable decrease in CRP among patients treated with $400 \mathrm{mg}$ dosing of certolizumab over the study period.

Although these were the some of the first studies to demonstrate the role of CRP as an inclusion criterion, early trials of anti-TNF agents included serial measurement of CRP (10-12). In the original infliximab induction trial published by Targan et al (10), there was a significant decrease in CRP level among patients treated with infliximab (monoclonal cA2) at four weeks (eg, $16 \mathrm{mg} / \mathrm{L}$ in those treated with $5 \mathrm{mg} / \mathrm{kg}$ infliximab versus $2 \mathrm{mg} / \mathrm{kg}$ in placebo). Normal serum CRP levels were maintained among patients who received maintenance therapy with infliximab (12). The pediatric infliximab literature similarly suggests a decrease in CRP in association with infliximab therapy in CD (13). The Clinical Assessment of Adalimumab Safety and Efficacy Studied as Induction Therapy in Crohn's Disease (CLASSIC-1) trial, which explored induction with adalimumab in $\mathrm{CD}$, reproduced the infliximab findings by showing a durable reduction in CRP over four weeks in patients treated with anti-TNF therapy (14).

Clinical trials exploring combination therapy have similarly included CRP as an outcome. The study by van Assche et al (15), which explored the discontinuation of immunosuppressants in $\mathrm{CD}$ patients on infliximab at six months, was particularly revealing as to the potential of this biomarker. The study authors demonstrated a significant increase in CRP in patients discontinuing immunosuppressants, 
although there was no difference in their primary outcome of patients requiring modification in infliximab dosing. Post hoc analysis demonstrated a correlation between CRP and serum trough levels of infliximab, and low trough levels were associated with higher median CRP levels. Analysis of data from the Study of Biologic and Immunomodulator Naive Patients in Crohn's Disease (SONIC) trial also demonstrated the best therapeutic results among patients with an elevated CRP level (16), as reported in monotherapy trials of anti-TNF agents.

Collectively, these trials raise several important questions. First, a majority of anti-TNF trials have included CRP measurement, and show significant decreases in CRP in the trial arm with higher rates of response and remission. However, little post hoc analysis has been performed to explore correlations between clinical and endoscopic end points of remission and CRP. Some of the best evidence comes from analysis of A Crohn's Disease Clinical Trial Evaluating Infliximab in a New Long-term Treatment regimen (ACCENT I) data by Reinisch et al (17). The central hypothesis was that CRP levels at baseline and 14 weeks are predictive of durable response/ remission, in this case between 14 weeks to one year after induction with infliximab. As shown in other trials, their results suggested an association between high baseline CRP and maintenance of remission in CD treated with infliximab. They also demonstrated that in responders, $\mathrm{CRP}<5 \mathrm{mg} / \mathrm{L}$ at week 14 was associated with maintenance of response $(56.6 \%$ of patients versus $37 \%$ of patients with a $\mathrm{CRP} \geq 5 \mathrm{mg} / \mathrm{L}$ ) and, furthermore, that a CRP level drop from $>5 \mathrm{mg} / \mathrm{L}$ to $<5 \mathrm{mg} / \mathrm{L}$ (ie, normalization) was associated with significant probability of remaining in remission (55\% versus 36\%). Nonetheless, the ROC curve of baseline CRP as a predictor of response after 14 weeks suggests no optimal cut-off point and, thus, it is difficult to make firm clinical suggestions about the role of CRP in effecting a therapeutic change at 14 weeks.

A second question that arises about CRP from CD trials of antiTNF agents is whether CRP is a general measure of systemic inflammation, versus a specific predictor of a disease phenotype that is responsive to anti-TNF agents. Recent investigation of novel biologic agents that target different inflammatory pathways, including the interleukin 23/Th17 axis and leukocyte adhesion, sheds further light on this question. A study assessing the use of ustekinumab for induction and maintenance therapy in refractory Crohn's disease explored use of ustekinumab, an anti-interleukin 12/23 p40 agent, in induction and maintenance of CD resistant to anti-TNF treatment (18). There was a significant reduction in mean CRP levels in patients receiving 6 $\mathrm{mg} / \mathrm{kg}$ of ustekinumab induction versus placebo; reductions were sustained only in those receiving ustekinumab maintenance therapy. One reason for choosing anti-TNF-experienced patients in this trial was the demonstration of greater effect on CRP reduction in this subgroup (19). Further consistent with the hypothesis that CRP is a therapyindependent biomarker of response to therapy is the demonstration of changes in CRP in response to anti-integrin therapy. Studies suggest a significant decrease in CRP level in patients treated with natalizumab, among those with an elevated baseline CRP $(20,21)$. This finding was not reproduced in the recent trial of vedolizumab (22).

In addition to biologic trials, thiopurine trials have confirmed CRP as a key biomarker predictive of relapse. Two studies exploring thiopurine withdrawal $(23,24)$ demonstrated an elevated CRP level to be an independent predictor of relapse after withdrawal of azathioprine, in addition to a low hemoglobin level. Among patients treated with combination therapy, in whom infliximab is discontinued, CRP is also a predictor of relapse (25). However, the CRP cut-off used in these trials varied, between $5 \mathrm{mg} / \mathrm{mL}$ and $20 \mathrm{mg} / \mathrm{L}$.

CRP in UC: Few RCTs assessing medical therapy in active UC have used CRP as an end point. An early multicentre prospective RCT designed to assess the efficacy, safety and tolerability of infliximab used CRP as a secondary end point (26). Eleven UC patients with severe, steroid-refractory disease were treated with a single dose of infliximab at $5 \mathrm{mg} / \mathrm{kg}, 10 \mathrm{mg} / \mathrm{kg}$ or $20 \mathrm{mg} / \mathrm{kg}$, and the authors reported a decrease in CRP associated with clinical response. While $>50 \%$ of patients enrolled to the Active Ulcerative Colitis (ACT) 1 and ACT 2 trials had an elevated CRP at enrollment, changes were not reported as a marker of response to treatment (27).

Other, smaller studies have included CRP measurement. A headto-head trial of intravenous heparin and steroid therapy for moderate and severe UC in hospitalized patients included a secondary analysis focusing on changes in serological inflammatory indexes (28). In the first 10 days of treatment, a significant decrease in the CRP levels was observed in the steroid group, with no change in the heparin group. None of the heparin-treated patients showed an improvement in disease activity. An open-label randomized study involving 30 pediatric patients, comparing oral beclomethasone for eight weeks followed by oral mesalazine with oral mesalazine alone (29), demonstrated decreased ESR in both treatments arms by week 12; CRP level only dropped significantly in the beclomethasone group. There was concomitant reduction in clinical activity in the beclomethasone group.

The role of CRP in UC patients receiving anti-integrin therapy remains unclear. In patients receiving a single infusion of natalizumab, there was reduction in median CRP level two weeks postinfusion (30). However, the more recent induction and maintenance trials of vedolizumab did not include CRP level as an outcome (22).

In severe UC, baseline CRP elevation is a predictor of failure of medical therapy (31-33). A study involving 72 patients with steroidrefractory UC patients treated with oral or intravenous cyclosporin demonstrated a significant association of colectomy at three months with baseline CRP $(11.8 \mathrm{mg} / \mathrm{L}$ in the colectomy group versus $5.5 \mathrm{mg} / \mathrm{L})$ (34). However, a multivariate analysis found only the Ho index to be an independent predictor of colectomy, or treatment failure. Another retrospective chart review involving 135 patients with steroid-refractory UC treated with cyclosporine (35) found a CRP $>45 \mathrm{mg} / \mathrm{L}$ to be predictive for colectomy. The Oxford score, designed following a prospective study involving hospitalized patients with acute severe UC, also includes a CRP $>45 \mathrm{mg} / \mathrm{L}$ in patients with four to eight bowel movements per day as a predictor of colectomy (36). Elevated CRP level has been associated specifically with severe clinical activity, anemia and hypoalbuminemia, in addition to active disease on endoscopy $(7,37)$.

Clinical disease activity scores have generally been used as primary end points in UC RCTs. Some of these clinical measures, such as the Truelove \& Witts' criteria, Seo and Ho indexes, integrate biomarkers such as albumin, hemoglobin, ESR and CRP into their scoring. However, associations between biomarkers and response to therapy are generally not reported in RCTs.

Other peripheral blood biomarkers: Several other common laboratory tests have potential applicability in monitoring IBD, although they are not as well studied as CRP. Simple values derived from the complete blood count, including hemoglobin level and leukocyte counts, have demonstrated some utility in this context $(23,25)$. In the aforementioned study by Louis et al (25), a hemoglobin level $\leq 145 \mathrm{~g} / \mathrm{L}$ and a leukocyte count of $>6 \times 10^{9} / \mathrm{L}$ were both associated with decreased time-to-relapse in $\mathrm{CD}$ patients in whom infliximab therapy was stopped (HR 6.0 and 2.4, respectively). Interestingly, the HR was greater for hemoglobin than any other measured factor. Similarly, a study of azathioprine withdrawal found an association between a hemoglobin level $<120 \mathrm{~g} / \mathrm{L}$ and risk of relapse (23). Hypoalbuminemia and anemia are both associated with failure of medical therapy in severe ulcerative colitis (31). Nonetheless, there remains concern as to the sensitivity and specificity of these tests as biomarkers in IBD, given their variability in many disease states.

\section{FECAL BIOMARKERS}

\section{Summary}

In CD and UC, fcalpro should not be used alone as a treatment target because it has inadequate operational characteristics to act as a surrogate for endoscopic, radiographic or clinical end points. Fcalpro is a noninvasive adjunctive measure that can be used in both CD and UC to guide need for further endoscopic or radiographic evaluation. 
In $\mathrm{CD}$, fcalpro may especially useful in Crohn's colitis as a biomarker of response to therapy and to predict relapse. In UC, fcalpro likely has greater utility than CRP as an adjunctive measure to guide need for further investigation. Fcalpro has been shown to correlate with mucosal healing and response to induction therapy, and is predictive of loss of response to maintenance therapy in UC.

\section{Discussion}

Fcalpro: While blood-based biomarkers offer insight into systemic inflammation occurring as part of active IBD, fecal assays have the potential advantage of better reflecting inflammation at the mucosal level. Several different assays have been developed, most prominently those using calprotectin and lactoferrin as biomarkers. Both of these tests leverage the fact that actively inflamed bowel contains a large number of neutrophils and, furthermore, that the mucosal defects that occur during active inflammation result in spillover of neutrophils into stool. Calprotectin has become a more widely used assay, both because of better operational characteristics and the increasing availability of a rapid test.

Calprotectin is a calcium- and zinc-binding neutrophilic cystolic protein. It is an appropriate marker for mucosal inflammation, given that it is evenly distributed and stable in stool for up to one week $(38,39)$. This protein can be measured using commercially available ELISA or more recently developed quantitative rapid tests (40), although there are data suggesting that quantitation is less accurate with a rapid test (PreventID Caldetect, Preventis GmbH, Germany) at values $>15 \mu \mathrm{g} / \mathrm{g}(40)$. A major interest lies in the use of fcalpro to distinguish IBD from non-IBD (41), with studies reporting a sensitivity between $63 \%$ and $100 \%$, and specificity of $48 \%$ to $100 \%$, depending on trial design and fcalpro cut-off value (41). Several studies have demonstrated correlation between endoscopic/histological disease activity and fcalpro (42-45). This was first studied by Røseth et al (44) in patients with UC, who demonstrated increased correlation between endoscopic and histological grading of inflammation and fcalpro levels.

Fcalpro in CD: Recent work has suggested a correlation between fcalpro concentration and endoscopic disease activity in CD, and weaker associations with the CD activity index $(6,46)$. Correlation between elevated fcalpro and active disease is strongest in Crohn's colitis (Spearman coefficient 0.80 versus 0.45 for all CD) (6). This finding has been reproduced in the pediatric population (43). There is evidence that supports use of fcalpro for monitoring response to anti-TNF therapy. Sipponen et al (47) demonstrated a drop in mean fcalpro levels after therapy with anti-TNF agents (from $1173 \mu \mathrm{g} / \mathrm{g}$ to $130 \mu \mathrm{g} / \mathrm{g}$ ) (47); there was moderate correlation between change in fcalpro level and change in endoscopic activity using the CD Endoscopic Index of Severity (Spearman's rank-order correlation = 0.561), but not with ileal or colonic histological scores. Another study failed to demonstrate a significant change in fcalpro levels in patients who responded to medical therapy (48); however, both of these studies were limited by sample size $(n=15$ and $n=11 C D$ patients, respectively). Although similar to CRP, fcalpro is now used as an objective measure of inflammation for inclusion in clinical trials of novel agents $(49,50)$, few biologics trials report data regarding fcalpro in response to therapy.

There are data supporting the use of fcalpro to predict relapse in CD. In a prospective multicentre study, Gisbert et al (51) demonstrated that CD patients who relapsed within one year had significantly higher fcalpro levels at baseline. In this clinical context, fcalpro had a low sensitivity (28\%) but was highly specific (93\%). Collectively, it is difficult to suggest that fcalpro could replace endoscopic and clinical evaluation as a treatment target.

Fcalpro in UC: Fcalpro has been shown to correlate well with mucosal healing in ulcerative colitis $(46,52,53)$. D'Haens et al $(46)$ further reported that a fcalpro level $>250 \mu \mathrm{g} / \mathrm{g}$ predicted active mucosal disease (sensitivity of $71 \%$ and specificity of $100 \%$ ). Several studies have demonstrated that normalization of fcalpro predicts clinical response to medical therapies and sustained remission $(51,53,54)$. One study (52) assessed the use of fcalpro as a marker of sustained remission in UC patients receiving maintenance infliximab. Of 87 patients included in the study, 30 (34.4\%) were considered to be in sustained deep remission (defined as a partial Mayo score of 3 at all points and a Mayo endoscopic subscore 0 at week 52 ) and $13(14.9 \%)$ to have relapsed. Fcalpro levels remained low (median $40 \mu \mathrm{g} / \mathrm{g}$ ) throughout the study in those with sustained deep remission. Two consecutive fcalpro measurements of $300 \mu \mathrm{g} / \mathrm{g}$ at monthly intervals were identified as the best predictor of flare $(61.5 \%$ sensitive and $100 \%$ specific). In that study, fcalpro level at time of relapse was significantly better than serum CRP concentration at predicting relapse. In a pediatric hospitalized severe UC population, clinical scores were most predictive of steroid nonresponse; CRP and fcalpro levels could predict steroid response, although neither were found to be predictive of infliximab response (33).

Until recently, most therapeutics trials investigating UC have not included fecal biomarkers as secondary end points. Two recent studies assessing vedolizumab in UC included fcalpro measurement $(22,55)$. In the phase 3 trial in UC by Feagan et al (22), significant decreases in fcalpro were seen in the group receiving vedolizumab for induction and maintenance. An earlier vedolizumab dose-ranging study found decreases in the fcalpro corresponding with decrease in Mayo score; however, the sample size was inadequate to allow statistical analysis (55).

Lactoferrin: Lactoferrin is an iron-binding glycoprotein found in many body fluids, and is a major component of secondary granules of neutrophils (56). Similar to fcalpro, lactoferrin is very stable in feces over extended periods of time. However, some studies have suggested that fcalpro has better operational characteristics to distinguish IBD from non-IBD, and this, in part, has led to fcalpro becoming a more universally used and available biomarker $(57,58)$.

A prospective study of UC patients in remission on mesalamine found fcalpro to be more sensitive and specific than fecal lactoferrin for predicting UC relapse (54). A cut-off value of $170 \mu \mathrm{g} / \mathrm{g}$ for fcalpro had a sensitivity of $76 \%$ and a specificity of $76 \%$ to predict relapse, while a cut-off value of $140 \mu \mathrm{g} / \mathrm{g}$ for lactoferrin had a sensitivity of $67 \%$ and a specificity of $68 \%$. Others have shown similar results (51). There are data supporting the utility of lactoferrin for monitoring response to therapy (59); however, a major challenge remains significant overlap in fecal lactoferrin concentrations in patients with active and quiescent IBD (56).

\section{FUTURE BIOMARKERS}

With the advent of high-throughput systems and biology approaches, such as genomics, metagenomics and transcriptomics, it is likely that future biomarkers will result from integration of multiple metrics derived using these techniques. Gene expression profiling has found some utility in IBD; transcriptional profiles from biopsies of pediatric patients with severe UC predicts responsiveness to steroids (60). Polymorphisms in FOXO3 have been associated with more severe CD, despite not being associated with disease development (61).

In other immune-mediated diseases, systems biology approaches have directly impacted clinical care. For instance, gene expression profiling of peripheral blood in heart transplant patients has great potential in monitoring for rejection (62). Proteomic profiling of blood plasmacytoid dendritic cells in systemic sclerosis patients demonstrated an association between CXCL4 levels and severity as well as pulmonary involvement (63). In the case of IBD, future studies should expand on the potential use of bioinformatics platforms to develop biomarkers for use as surrogates of endoscopic outcomes.

DISCLOSURES: The authors have no financial disclosures or conflicts of interest to declare. 


\section{CONCLUSION}

As was suggested by consensus of the STRIDE program, currently available serum and fecal biomarkers do not possess adequate operational characteristics to make them stand-alone treatment targets in IBD; however, they should be considered important adjunctive measures to clinical, endoscopic and radiographic assessment. The present review demonstrated the continued value that biomarkers provide in alerting the clinician to a need for further investigation. As the strategy of 'treat-to-target' becomes more widespread in IBD management, it becomes crucial to define noninvasive measures that reliably reflect clinical and endoscopic disease activity. The development of more accurate biomarkers in IBD remains an important goal.

\section{REFERENCES}

1. Solomon DH, Bitton A, Katz JN, Radner H, Brown EM, Fraenkel L. Review: Treat to target in rheumatoid arthritis: Fact, fiction, or hypothesis? Arthritis Rheumatol 2014;66:775-82.

2. Pepys MB, Hirschfield GM. C-reactive protein: A critical update. J Clin Invest 2003;111:1805-12.

3. Szalai AJ, McCrory MA, Cooper GS, Wu J, Kimberly RP. Association between baseline levels of C-reactive protein (CRP) and a dinucleotide repeat polymorphism in the intron of the CRP gene. Genes Immun 2002;3:14-9.

4. Carlson CS, Aldred SF, Lee PK, et al. Polymorphisms within the C-reactive protein (CRP) promoter region are associated with plasma CRP levels. Am J Hum Genet 2005;77:64-77.

5. Colombel JF, Solem CA, Sandborn WJ, et al. Quantitative measurement and visual assessment of ileal Crohn's disease activity by computed tomography enterography: Correlation with endoscopic severity and C reactive protein. Gut 2006;55:1561-7.

6. Jones J, Loftus EV, Panaccione R, Chen LS. Relationships between disease activity and serum and fecal biomarkers in patients with Crohn's Disease. Clin Gastroenterol Hepatol 2008;6:1218-24.

7. Solem CA, Loftus EV, Tremaine WJ, Harmsen WS, Zinsmeister AR, Sandborn WJ. Correlation of C-reactive protein with clinical, endoscopic, histologic, and radiographic activity in inflammatory bowel disease. Inflamm Bowel Dis 2005;11:707-12.

8. Sandborn WJ, Feagan BG, Stoinov S, et al. Certolizumab pegol for the treatment of Crohn's disease. N Engl J Med 2007;357:228-38.

9. Schreiber S, Rutgeerts P, Fedorak RN, et al. A randomized, placebocontrolled trial of certolizumab pegol (CDP870) for treatment of Crohn's disease. Gastroenterology 2005;129:807-18.

10. Targan SR, Hanauer SB, van Deventer SJ, et al. A short-term study of chimeric monoclonal antibody cA2 to tumor necrosis factor alpha for Crohn's disease. Crohn's Disease cA2 Study Group. N Engl J Med 1997;337:1029-35.

11. Stack WA, Mann SD, Roy AJ, et al. Randomised controlled trial of CDP571 antibody to tumour necrosis factor-alpha in Crohn's disease. Lancet 1997;349:521-4.

12. Rutgeerts P, D'Haens G, Targan S, et al. Efficacy and safety of retreatment with anti-tumor necrosis factor antibody (infliximab) to maintain remission in Crohn's disease. Gastroenterology 1999;117:761-9.

13. Lamireau T, Cézard J-P, Dabadie A, et al. Efficacy and tolerance of infliximab in children and adolescents with Crohn's disease. Inflamm Bowel Dis 2004;10:745-50.

14. Hanauer SB, Sandborn WJ, Rutgeerts P, et al. Human anti-tumor necrosis factor monoclonal antibody (adalimumab) in Crohn's disease: The CLASSIC-I trial. Gastroenterology 2006;130:323-3.

15. van Assche G, Magdelaine-Beuzelin C, D'Haens G, et al. Withdrawal of immunosuppression in Crohn's disease treated with scheduled infliximab maintenance: A randomized trial. Gastroenterology 2008;1341861-8.

16. Colombel JF, Sandborn WJ, Reinisch W, et al. Infliximab, azathioprine, or combination therapy for Crohn's disease. N Engl J Med 2010;362:1383-95.

17. Reinisch W, Wang Y, Oddens BJ, Link R. C-reactive protein, an indicator for maintained response or remission to infliximab in

\section{APPENDIX 1}

The following search strategy was used on PubMed, with filters for only human studies, and only English results.

("calprotectin"[Title/Abstract] OR "lactoferrin"[Title/Abstract] OR “c-reactive protein"[Title/Abstract] OR "CRP"[Title/Abstract] OR "erythrocyte sedimentation rate"[Title/Abstract] OR "ESR"[Title/Abstract]OR "hemoglobin"[Title/Abstract] OR "bone mineral density"[Title/Abstract] OR "ferritin"[Title/Abstract] OR "erythrocyte sedimentation rate"[Title/Abstract] OR "ESR"[Title/ Abstract]) AND ("ulcerative colitis"[Title/Abstract] OR “crohn disease"[Title/Abstract] OR “crohn's disease"[Title/Abstract] OR "crohns disease"[Title/Abstract] OR "inflammatory bowel disease"[Title/Abstract] OR “IBD”[Title/Abstract]) AND ("response"[Title/Abstract] OR "remission"[Title/Abstract] OR "Flare"[Title/Abstract]) AND (Clinical Trial[ptyp] OR Review[ptyp])

patients with Crohn's disease: A post-hoc analysis from ACCENT I. Aliment Pharmacol Ther 2012;35:568-76.

18. Sandborn WJ, Feagan BG, Fedorak RN, et al. A randomized trial of ustekinumab, a human interleukin-12/23 monoclonal antibody, in patients with moderate-to-severe Crohn's disease. Gastroenterology 2008;135:1130-41.

19. Toedter GP, Blank M, Lang Y, Chen D. Relationship of C-reactive protein with clinical response after therapy with ustekinumab in Crohn's disease. Am J Gastroenterol 2009;104:2768-73.

20. Ghosh S, Goldin E, Gordon FH, et al. Natalizumab for active Crohn's disease. N Engl J Med 2003;348:24-32.

21. MacDonald JK, McDonald JW. Natalizumab for induction of remission in Crohn's disease. Cochrane Database Syst Rev 2007;(1):CD006097.

22. Feagan BG, Rutgeerts P, Sands BE, et al. Vedolizumab as induction and maintenance therapy for ulcerative colitis. N Engl J Med 2013;369:699-710.

23. Treton X, Bouhnik Y, Mary J-Y, et al. Azathioprine withdrawal in patients with Crohn's disease maintained on prolonged remission: A high risk of relapse. Clin Gastroenterol Hepatol 2009;7:80-5.

24. Lémann M, Mary J-Y, Colombel J-F, et al. A randomized, doubleblind, controlled withdrawal trial in Crohn's disease patients in long-term remission on azathioprine. Gastroenterology 2005;128:1812-8.

25. Louis E, Mary J-Y, Vernier-Massouille G, et al. Maintenance of remission among patients with Crohn's disease on antimetabolite therapy after infliximab therapy is stopped. Gastroenterology 2012;142:63-70.e5.

26. Sands BE, Tremaine WJ, Sandborn WJ, et al. Infliximab in the treatment of severe, steroid-refractory ulcerative colitis: A pilot study. Inflamm Bowel Dis 2001;7:83-8.

27. Rutgeerts P, Sandborn WJ, Feagan BG, et al. Infliximab for induction and maintenance therapy for ulcerative colitis. N Engl J Med 2005;353:2462-76.

28. Panes J, Esteve M, Cabre E, et al. Comparison of heparin and steroids in the treatment of moderate and severe ulcerative colitis. Gastroenterology 2000;119:903-8.

29. Romano C, Famiani A, Comito D, Rossi P, Raffa V, Fries W. Oral beclomethasone dipropionate in pediatric active ulcerative colitis: A comparison trial with mesalazine. J Pediatr Gastroenterol Nutr 2010;50:385-9.

30. Gordon FH, Hamilton MI, Donoghue S, et al. A pilot study of treatment of active ulcerative colitis with natalizumab, a humanized monoclonal antibody to alpha-4 integrin. Aliment Pharmacol Ther 2002;16:699-705.

31. Kumar S, Ghoshal UC, Aggarwal R, Saraswat VA, Choudhuri G. Severe ulcerative colitis: Prospective study of parameters determining outcome. J Gastroenterol Hepatol 2004;19:1247-52.

32. Henriksen M, Jahnsen J, Lygren I, et al. C-reactive protein: A predictive factor and marker of inflammation in inflammatory bowel disease. Results from a prospective population-based study. Gut 2008;57:1518-23.

33. Turner D, Mack D, Leleiko N, et al. Severe pediatric ulcerative colitis: A prospective multicenter study of outcomes and predictors of response. Gastroenterology 2010;138:2282-91. 
34. Aceituno M, Garcia-Planella E, Heredia C, et al. Steroid-refractory ulcerative colitis: Predictive factors of response to cyclosporine and validation in an independent cohort. Inflamm Bowel Dis 2008; $14: 347-52$.

35. Cacheux W, Seksik P, Lémann M, et al. Predictive factors of response to cyclosporine in steroid-refractory ulcerative colitis. Am J Gastroenterol 2008;103:637-42.

36. Travis SP, Farrant JM, Ricketts C, et al. Predicting outcome in severe ulcerative colitis. Gut 1996;38:905-10.

37. Ricanek P, Brackmann S, Perminow G, et al. Evaluation of disease activity in IBD at the time of diagnosis by the use of clinical, biochemical, and fecal markers. Scand J Gastroenterol 2011;46:1081-91.

38. Røseth AG, Fagerhol MK, Aadland E, Schjønsby H. Assessment of the neutrophil dominating protein calprotectin in feces. A methodologic study. Scand J Gastroenterol 1992;27:793-8.

39. Abraham BP, Kane S. Fecal markers: Calprotectin and lactoferrin. Gastroenterol Clin North Am 2012;41:483-95.

40. Vestergaard TA, Nielsen SL, Dahlerup JF, Hornung N. Fecal calprotectin: Assessment of a rapid test. Scand J Clin Lab Invest 2008;68:343-7.

41. Burri E, Beglinger C. Faecal calprotectin - a useful tool in the management of inflammatory bowel disease. Swiss Med Wkly 2012;142:w13557.

42. Konikoff MR, Denson LA. Role of fecal calprotectin as a biomarker of intestinal inflammation in inflammatory bowel disease. Inflamm Bowel Dis 2006;12:524-34.

43. Bunn SK, Bisset WM, Main MJ, Gray ES, Olson S, Golden BE. Fecal calprotectin: Validation as a noninvasive measure of bowel inflammation in childhood inflammatory bowel disease. J Pediatr Gastroenterol Nutr 2001;33:14-22.

44. Røseth AG, Aadland E, Jahnsen J, Raknerud N. Assessment of disease activity in ulcerative colitis by faecal calprotectin, a novel granulocyte marker protein. Digestion 1997;58:176-80.

45. Limburg PJ, Ahlquist DA, Sandborn WJ. Fecal calprotectin levels predict colorectal inflammation among patients with chronic diarrhea referred for colonoscopy. Am J Gastroenterol 2000;95:2831-7.

46. D'Haens G, Ferrante M, Vermeire S, et al. Fecal calprotectin is a surrogate marker for endoscopic lesions in inflammatory bowel disease. Inflamm Bowel Dis 2012;18:2218-24.

47. Sipponen T, Savilahti E, Kärkkäinen P, et al. Fecal calprotectin, lactoferrin, and endoscopic disease activity in monitoring anti-TNFalpha therapy for Crohn's disease. Inflamm Bowel Dis 2008;14:1392-8.

48. Wagner M, Peterson CGB, Ridefelt P, Sangfelt P, Carlson M. Fecal markers of inflammation used as surrogate markers for treatment outcome in relapsing inflammatory bowel disease. World J Gastroenterol 2008;14:5584-9.

49. Sandborn WJ, Feagan BG, Rutgeerts P, et al. Vedolizumab as induction and maintenance therapy for Crohn's disease. N Engl J Med 2013;369:711-21.

50. Hueber W, Sands BE, Lewitzky S, et al. Secukinumab, a human anti-IL-17A monoclonal antibody, for moderate to severe Crohn's disease: Unexpected results of a randomised, double-blind placebocontrolled trial. Gut 2012;61:1693-700.

51. Gisbert JP, Bermejo F, Perez-Calle J-L, et al. Fecal calprotectin and lactoferrin for the prediction of inflammatory bowel disease relapse. Inflamm Bowel Dis 2009;15:1190-8.

52. De Vos M, Louis EJ, Jahnsen J, et al. Consecutive fecal calprotectin measurements to predict relapse in patients with ulcerative colitis receiving infliximab maintenance therapy. Inflamm Bowel Dis 2013;19:2111-7.

53. Molander P, af Björkesten C-G, Mustonen H, et al. Fecal calprotectin concentration predicts outcome in inflammatory bowel disease after induction therapy with TNF $\alpha$ blocking agents. Inflamm Bowel Dis 2012;18:2011-7.

54. Yamamoto T, Shiraki M, Bamba T, Umegae S, Matsumoto K. Fecal calprotectin and lactoferrin as predictors of relapse in patients with quiescent ulcerative colitis during maintenance therapy. Int J Colorectal Dis 2014;29:485-91.

55. Parikh A, Leach T, Wyant T, et al. Vedolizumab for the treatment of active ulcerative colitis: A randomized controlled phase 2 dose-ranging study. Inflamm Bowel Dis 2012;18:1470-9.

56. Gisbert JP, McNicholl AG, Gomollon F. Questions and answers on the role of fecal lactoferrin as a biological marker in inflammatory bowel disease. Inflamm Bowel Dis 2009;15:1746-54.

57. Silberer H, Küppers B, Mickisch O, et al. Fecal leukocyte proteins in inflammatory bowel disease and irritable bowel syndrome. Clin lab 2005; 51:117-26.

58. Schröder O, Naumann M, Shastri Y Prospective evaluation of faecal neutrophil-derived proteins in identifying intestinal inflammation: Combination of parameters does not improve diagnostic accuracy of calprotectin. Aliment Pharmacol Ther 2007;26:1035-42.

59. Turner D, Leach ST, Mack D, et al. Faecal calprotectin, lactoferrin, M2-pyruvate kinase and S100A12 in severe ulcerative colitis: A prospective multicentre comparison of predicting outcomes and monitoring response. Gut 2010;59:1207-12.

60. Kabakchiev B, Turner D, Hyams J, et al. Gene expression changes associated with resistance to intravenous corticosteroid therapy in children with severe ulcerative colitis. PLoS ONE 2010;5:e13085.

61. Lee JC, Espéli M, Anderson CA, et al. Human SNP links differential outcomes in inflammatory and infectious disease to a FOXO3-regulated pathway. Cell 2013;155:57-69.

62. Pham MX, Teuteberg JJ, Kfoury AG, et al. Gene-expression profiling for rejection surveillance after cardiac transplantation. N Engl J Med 2010;362:1890-900.

63. van Roon JAG, Tesselaar K, Radstake TRDJ. Proteome-wide analysis and CXCL4 in systemic sclerosis. N Engl J Med 2014;370:1563-4.

64. D'Inca R, Dal Pont E, Di Leo V, et al. Can calprotectin predict relapse risk in inflammatory bowel disease? Am J Gastroenterol 2008;103:2007-14. 


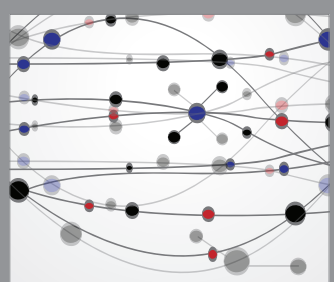

The Scientific World Journal
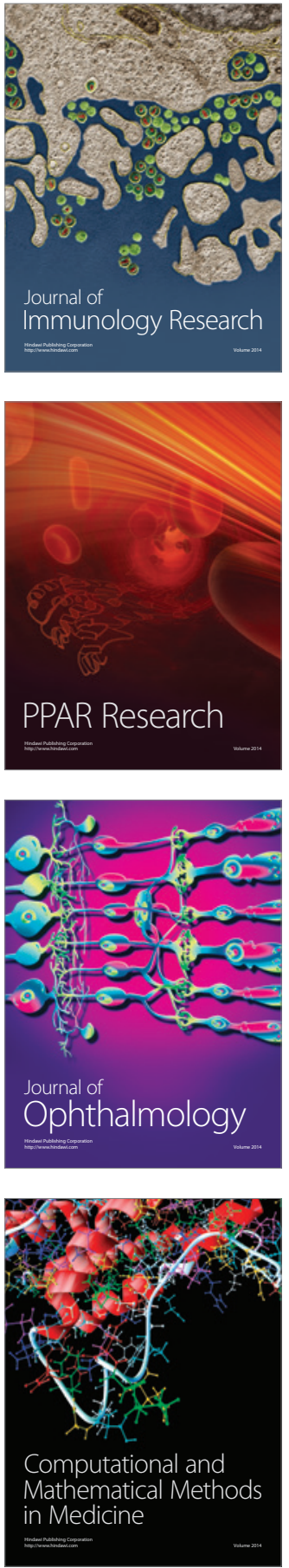

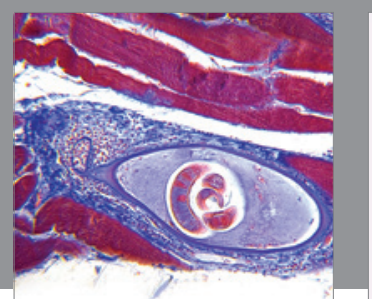

Gastroenterology Research and Practice

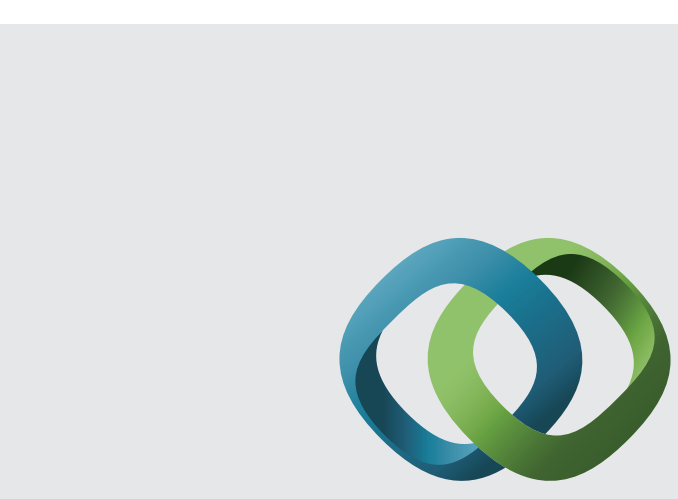

\section{Hindawi}

Submit your manuscripts at

http://www.hindawi.com
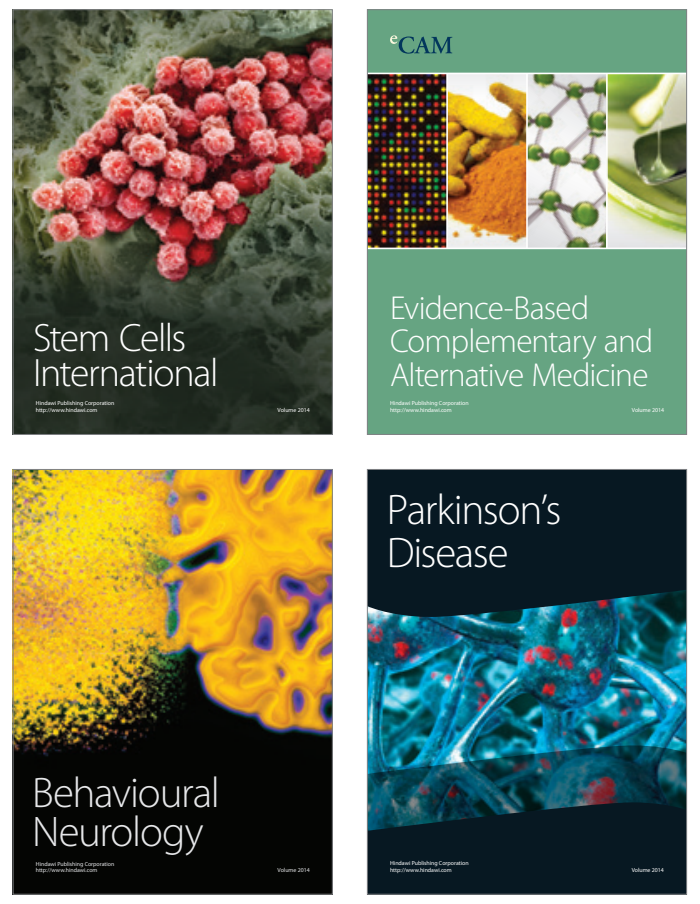
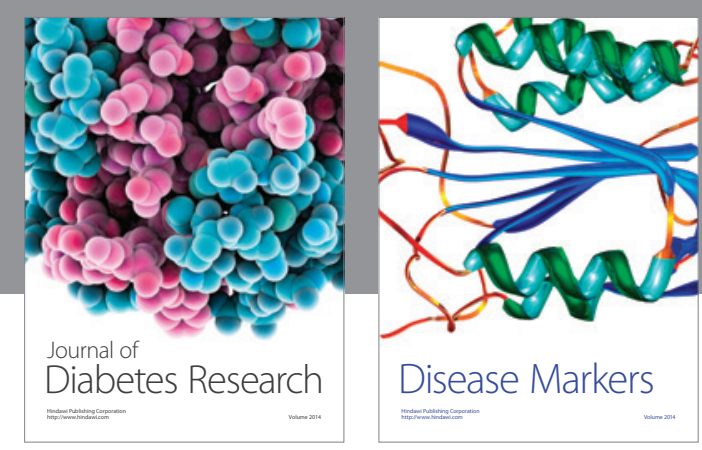

Disease Markers
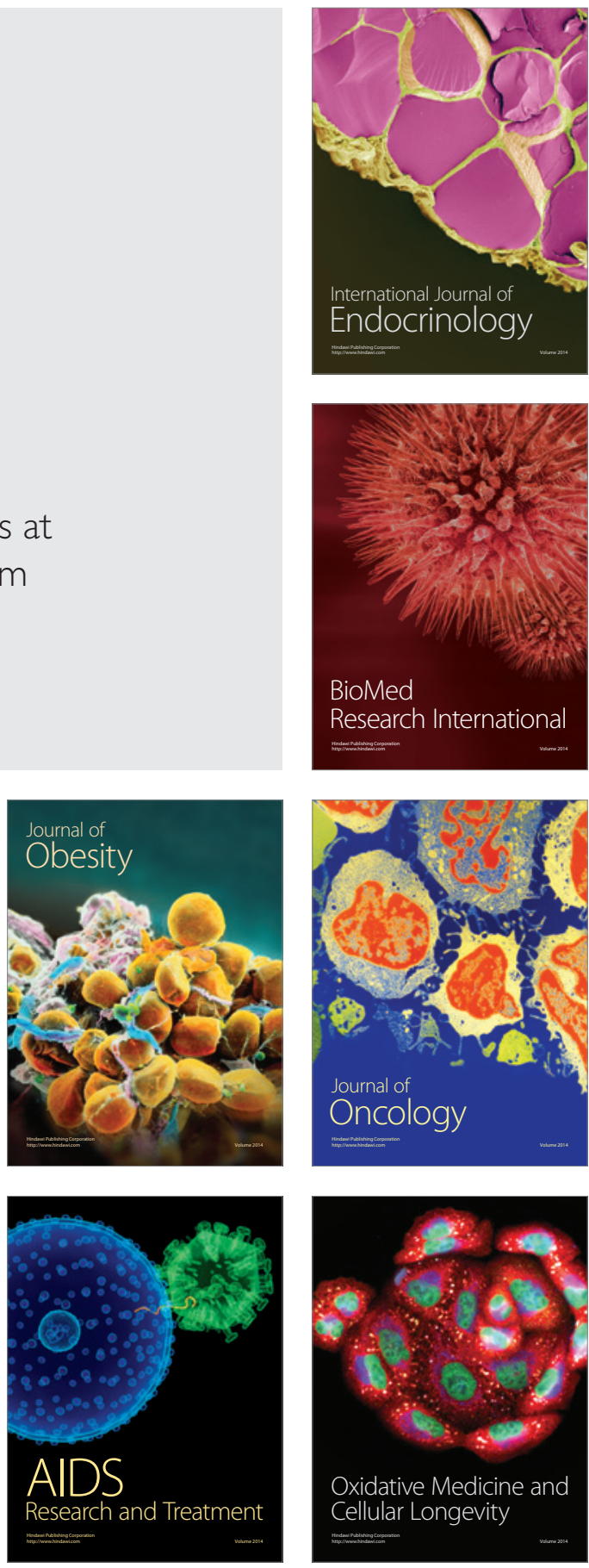